NOTAS 


\title{
LA GEOGRAFÍA Y LAS DISTINTAS ACEPCIONES DEL ESPACIO GEOGRÁFICO
}

\author{
Félix Pillet Capdepón \\ Departamento de Geografía y Ordenación del Territorio \\ Universidad de Castilla-La Mancha
}

\section{RESUMEN}

Con la incorporación de la geografía como ciencia social desde mediados del siglo $\mathrm{XX}$, el estudio del espacio regional o concreto dio paso a distintas acepciones del espacio geográfico (abstracto, subjetivo y social) de la mano de diversos paradigmas, para concluir con el acercamiento de unas corrientes de pensamiento con otras, con un eclecticismo científico preocupado por el actual espacio local globalizado.

Palabras clave: ciencia social, espacio geográfico, eclecticismo, espacio local globalizado.

\begin{abstract}
After the acknowledgement of geography as a social science since the middle of the 20th century, the study of regional or concrete space gave way to various meanings of the geographical space (abstract, subjective and social). This was brought by various paradigms, which aimed at the raprochement of the different streams of thought, resulting in a scientific eclecticism preoccupied by today's globalised local space.
\end{abstract}

Key words: social science, geographical space, scientific eclecticism, globalised local space.

\section{Introducción}

La geografía se deslizó hacia la defensa de la condición social como elemento identificador, entendida en tanto que ciencia humana o social desde mediados del siglo XX, entrando a formar parte de las restantes ciencias sociales (Capel, 1987: 21-22), siendo su principal objetivo los procesos que determinan la diferenciación espacial. 
Dentro del pensamiento dialéctico, Habermas defendió su teoría crítica como síntesis de la modernidad y la posmodernidad. Frente a esta situación dual, la teoría crítica intenta sintetizar la visión funcionalista (sociedad como sistema) con la fenomenológica (sociedad como mundo de la vida), apoyándose en la teoría de la acción comunicativa (Habermas, 1988) síntesis de la hermenéutica-crítica, opuesta al positivismo cuantitativo, y en definitiva, como un movimiento reconstructivista en pro de la comunicación y el consenso. Habermas agrupó los distintos paradigmas que han influido en las ciencias sociales en tres grupos: ciencias empírico-analíticas (positivismo lógico), ciencias histórico-hermenéuticas (fenomenología), y ciencias críticas, relacionando cada una de ellas con un interés cognoscitivo: técnico, práctico y emancipatorio, respectivamente (Habermas, 1982). Kemmis siguiendo a este autor señalará que cada ciencia está al servicio de los intereses humanos y sociales de distinta forma: las ciencias empírico-analíticas se centran en la reflexión o el interés práctico; las histórico-hermenéuticas en la acción, en el contexto social; y por último, las críticas, al servicio de la sociedad, las identifica con la distorsión de nuestro pensamiento y acción por la ideología (Kemmis, 1999: 102).

Para relacionar los paradigmas geográficos con los del conjunto de las ciencias sociales nos ha parecido oportuno utilizar la relación que establece Unwin con la división de las ciencias de Habermas. El resultado de dicha relación sería el siguiente: las geografías neopositivistas (teorética y sistémica) se interpretarán en el contexto de las ciencias empírico-analíticas; la geografía de la percepción y del comportamiento, así como la geografía humanística o humanista serán consideradas como ciencias histórico-hermenéuticas; la geografía radical, la geografía realista y la geografía posmoderna dentro de las ciencias críticas; quedando por último, el eclecticismo actual anti o pospositivista (Pillet, 2001).

Si la geografía es una ciencia espacial y «el espacio sólo es geográfico en relación con el hombre» (Arroyo y Pérez, 1997: 524), las distintas acepciones que el espacio geográfico ha ido adoptando en función de los diversos paradigmas, han originado un objeto o enfoque distinto, mientras la geografía regional (historicista o posibilista) de la primera parte del siglo XX se dedicó al estudio del espacio concreto o regional, dando cabida a una combinación errónea de las ciencias naturales y sociales; las corrientes geográficas de la segunda parte del siglo XX (Olcina, 1996: 96), que ahora analizaremos, se centraron en el contexto de las ciencias sociales:

- las geografías neopositivistas o empírico-analíticas: el espacio abstracto.

- las geografías histórico-hermenéuticas: el espacio subjetivo

- las geografías críticas: el espacio social

- y el actual eclecticismo geográfico: el espacio local globalizado.

\section{El espacio abstracto}

El positivismo lógico o neopositivismo reafirmó los principios básicos del viejo positivismo: la neutralidad de la ciencia, el método hipotético-deductivo, el lenguaje científicomatemático; y el rechazo a la metafísica, al historicismo, y a los métodos cualitativos. La creencia equivocada de que los paradigmas nacían, se desarrollaban y morían, originó que se hablara de «nueva geografía» o geografía neopositivista con sus dos aportaciones la análítica o teorética y la sistémica.

Desde la obra crítica con el posibilismo geográfico Excepcionalismo en Geografía de F.K. Schaeffer (1953), esta corriente pretendía convertir a la geografía en ciencia nomotética, capaz de establecer las leyes que rigen la ordenación espacial a partir del lenguaje matemático y de las teorías de la localización, especialmente los modelos geométricos 

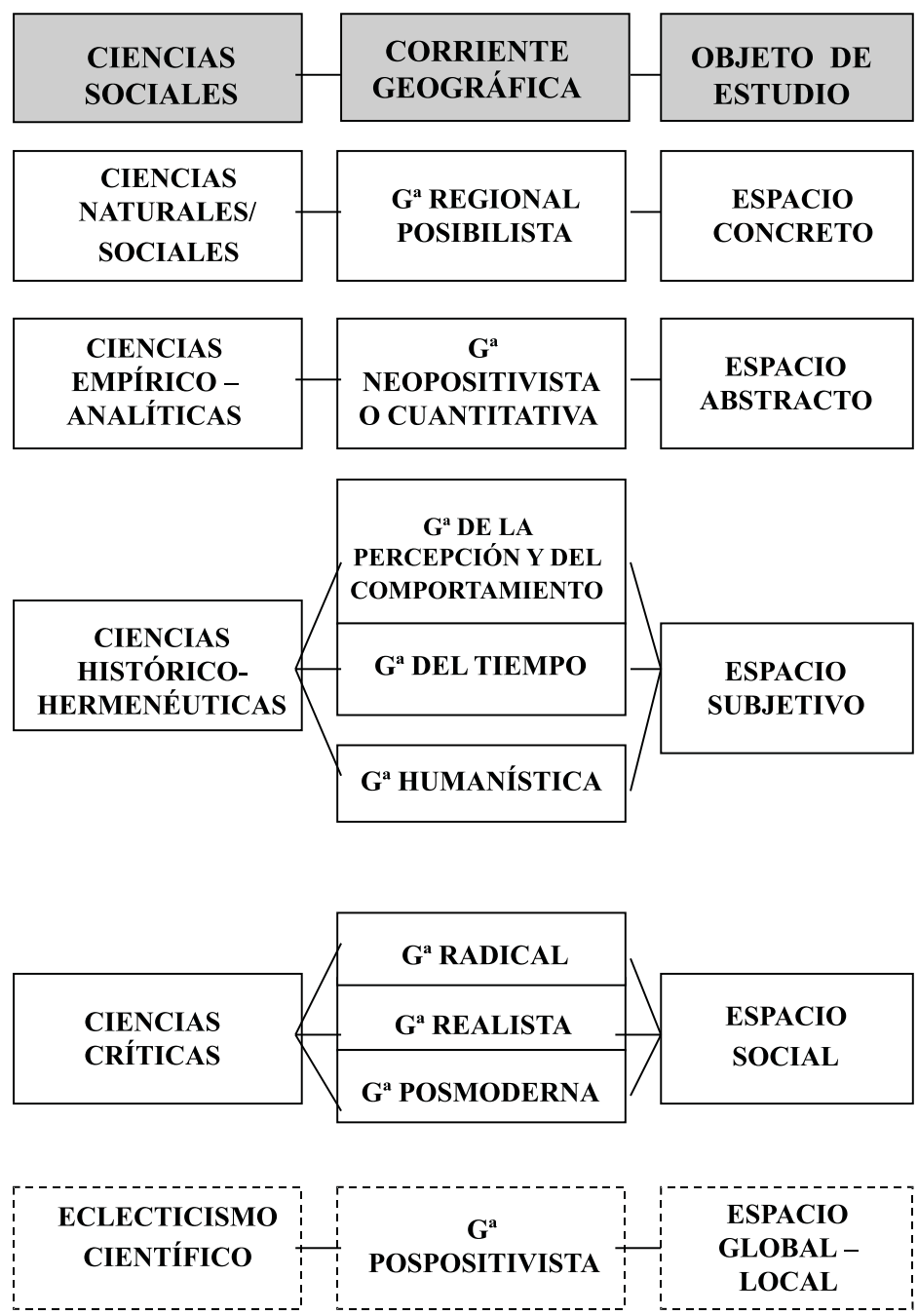

propuestos hasta los años cuarenta. Sus principales teóricos reclamaban nuevos modelos o estructuras simplificadas de la realidad que dieran respuesta a los problemas espaciales de la segunda parte del siglo XX, a la vez que conectaran la geografía física con la humana (Chorley y Haggett, 1971: 12). Se afirmaba que «el medio natural, ha venido a ser reemplazado por un medio ambiente, en gran medida obra del hombre, que está subordinado al entorno socioeconómico» (Chorley, 1975: 234). En esta misma línea se confirmaba desde la geografía física que «las circunstancias han llevado a la Geografía física al enfoque medioambiental en el que se unen ciencia y servicio a los intereses del hombre» (Sala y Batalla, 1975: 19-20). El espacio de la geografía teorética se convierte en el eje del discurso y de la práctica geográfica, «no trata ni de fenómenos naturales ni de fenómenos culturales, sino de fenómenos espaciales» (Muñoz, 1989: 225). 
La sustitución de un empirismo, resultado de la observación directa de la geografía regional, por otro más abstracto que ofreció una excesiva «geometrización» del espacio con escaso avance teórico (Estébanez y Pérez, 1990: 26) y ausente de soluciones a los verdaderos problemas, demostró que los modelos eran estáticos, que no prestaban atención a la dinámica espacial. Su metodología se había convertido en un fin en sí misma, en una filosofía que al optar por la neutralidad, obviaba la problemática social al no aportar soluciones a los problemas sociales, económicos y ambientales.

Con la introducción de la Teoría de los Sistemas de Bertalanffy (1968) la geografía teorética dio paso a la geografía sistémica, con ella se podía definir en términos lógicos y matemáticos el análisis geográfico de los espacios regionales, pasando la región a ser contemplada como un sistema abierto o como regiones polarizadas. Se produce, también, un renacimiento del interés de los geógrafos por el paisaje, redefinido en términos sistémicos, desde una línea de investigación geo-ecológica impulsada por Troll que ha dado lugar a lo que genéricamente se ha conocido como análisis integrado de paisajes (Muñoz, 1989: 226-230), interpretando el geosistema como una combinación sistémica. Con una base sistémica y estructural, pero centrada en los aspectos humanos aparece la geografía coremática, esbozada en 1967 y desarrollada en 1990 por Brunet. Se preocupaba por las configuraciones espaciales que contemplaba el espacio desde una dimensión geométrica, prescindiendo de lo físico o considerándolo sólo de forma secundaria.

La «nueva geografía» recibió las primeras críticas internas desde los planteamientos conductistas a mediados de los sesenta, a ellas se unieron, al final de la década, el abandono de teóricos como Bunge y Harvey que optaron por la defensa del espacio social que defendería la geografía radical. La geografía sistémica sigue siendo defendida por los geógrafos físicos «Mientras que la mayoría de los geógrafos físicos se apoyan en la certeza de la ciencia empírico-analítica, bajo el aspecto falaz del denominado método científico, la mayoría de los geógrafos humanos han presentado sus credenciales ante una ciencia social dominada por las concepciones histórico-hermenéutica y estructuralista de la ciencia» (Unwin, 1995: 74).

De la influencia cuantitativa ha quedado el interés por las técnicas instrumentales y por los Sistemas de Información Geográfica, estos han abierto un campo de excepcionales perspectivas, un marchamo de modernidad, y una evidente recuperación de las geografías positivistas o empíricas (Ortega, 2000: 280-281).

\section{El espacio subjetivo}

Desde dentro del movimiento positivista y en reacción a sus propuestas surgieron dos corrientes geográficas preocupadas por las respuestas subjetivas frente al espacio, nos referimos a la geografía de la percepción y del comportamiento. Se basaron en el conductismo o behaviorismo, método psicológico desarrollado por Watson que surgió como un intento de salvar al positivismo al analizar el comportamiento externo del hombre y su conducta. A estas geografías se uniría una nueva corriente que establecería sus conexiones con la geografía regional: la geografía humanística.

\subsection{La geografía de la percepción y del comportamiento}

En esta nueva aportación existen claramente dos etapas (Boira, 1992: 573-592), la geografía del comportamiento analítica, vinculada al positivismo, y la geografía de la percepción, a medio camino entre el positivismo y los planteamientos humanistas. La geografía del comportamiento analítica, aún repudiando los principios positivistas, si- 
guió manteniendo rasgos propios del pensamiento lógico y matemático, tales como las generalizaciones, la comprobación de hipótesis, y el lenguaje analítico; los temas de estudio preferidos se centran en el análisis de los modelos subyacentes al comportamiento espacial, en la toma de decisiones relacionadas con la utilidad y la elección espacial, en los problemas derivados de la localización, en los trayectos y distancias interurbanas, y por último, en la estructura de los mapas mentales. La geografía de la percepción optó por una situación ecléctica entre las orientaciones positivistas y humanistas, de los primeros adoptó el uso de técnicas y procedimientos de trabajo adaptados a la psicología, pero sus temas se centraron en la representación de la información espacial, propia de los humanistas.

Sus orígenes datan del primer quinquenio de los sesenta, cuando Gilbert White (1961) de la Universidad de Chicago estudió la respuesta ante los riesgos naturales basándose en la idea de que el comportamiento humano estaba directamente influido por la percepción. En esta misma línea, en Suecia, Julian Wolpert (1964) adoptó el modelo de comportamiento humano al conductismo ambiental. A mediados de la década siguiente Gould y White comenzaron a trabajar en los mapas mentales, con ellos pretendían identificar imágenes que guardaban los individuos de áreas concretas, tratando de relacionar la imagen con las características sociales y económicas que vivían los sujetos. Con este paso importante se pretendía sacar a la geografía de la deshumanización cuantitativista. La percepción humana y el espacio subjetivo se oponían al espacio objetivo o abstracto de los neopositivistas. Algunos críticos han puesto en duda, si la percepción individual pueda tener validez como método científico.

Antes de pasar a la geografía humanística, queremos recoger una pequeña aportación de una corriente conocida como cronogeografía o geografía del tiempo que tuvo su origen a finales de los sesenta en Suecia de la mano de Hägerstrand. Este autor ideó un modelo que combinaba las variables espacio y tiempo cronológico como limitadoras de la acción humana; propuesta que se utilizaría, una década después, para constatar la necesidad de planificar las actividades humanas en el tiempo y en el espacio, especialmente la jornada femenina en su doble actuación laboral y familiar (García Ramón, 1985: 61-63 y 109).

El método positivista-conductista que había desarrollado la geografía de la percepción y del comportamiento, así como la geografía del tiempo fue evolucionando hacia planteamientos próximos al enfoque fenomenológico-humanista.

\subsection{La geografía humanista o humanística}

Se ha afirmado que la preocupación por el estudio del espacio subjetivo no fue tenido en cuenta, de una forma expresa, hasta que esta corriente no puso su énfasis «en la dimensión subjetiva de esos espacios personales, particulares e individuales» (Arroyo y Pérez, 1997: 54). Su aportación se ha visto enriquecida por la influencia fenomenológica (Husserl y Schuzt), existencial (Sartre) e idealista (Collingwood), lo que ha posibilitado que se pueda hablar de tres líneas de actuación desde comienzos de los setenta: en primer lugar, la geografía humanística fenomenológica, centrada en el interés por el sujeto, por el individuo ante el medio material o mundo vivido. Retoma el concepto de lugar (vivido o sentido) para estudiarlo a partir de la experiencia, de la intuición, de la literatura, este fue el caso de los geógrafos Tuan, Relp y Buttimer. La geografía humanística existencial encierra un interés básico por las realidades de la condición humana y, como influencia marxista por la alienación, se preocupaba por los seres humanos, por la individualidad como demostraron Entrikin y Samuels. Y en tercer lugar, la geografía humanística idealista que recuperó para el humanismo el enfoque histórico, a la vez que 
se centró en el estudio del paisaje (diferente al estudiado por la geografía física), como resultado directo de la acción del hombre, según observaba Guelke.

Junto a la recuperación del lugar y del paisaje, un paisaje con toda su carga natural y social, histórico y actual, captado desde una renovada concepción integradora, el centro de atención de esta geografía se polarizó en el análisis de la región, como espacio vivido o de la experiencia cotidiana e histórica, y como identificación cultural. La región como identificación cultural pretendía ser útil para la planificación territorial, teniendo en cuenta la perspectiva histórica idealista, y la carga cultural del lugar, del territorio. Del legado humanista lo que ha ejercido mayor influencia es la reflexión sobre los conceptos de espacio y de lugar, sin olvidar que «del lugar a la región hay sólo un paso» (Nogué, 1989: 69). Una región que se convertía en punto de encuentro de los saberes científicos, literarios y populares (Gómez Mendoza, 1989: 106), que podía ser interpretada o leída como si de un texto se tratara, volviendo a recuperar a los viejos maestros de la geografía regional: Sauer o Terán.

Como otras corrientes, no estuvo libre de opiniones adversas, por haberse centrado en la visión individual, en las interpretaciones simbólicas, en el mundo de los significados, y en definitiva, en la pasividad social, al soslayar la implicación activa en los mecanismos del cambio social y político. A partir de los ochenta, los postulados humanísticos se confundirán e identificarán con los posmodernos, se ha afirmado que «las geografías humanísticas se transforman en geografías posmodernas» (Ortega, 2000: 299).

\section{El espacio social}

La contestación al positivismo lógico de la geografía cuantitativa o neopositivista tuvo su punto de partida en la reunión de la Asociación de Geógrafos Norteamericanos (1969) con la presentación de la revista Antipode, que se convertía en el principal órgano de expresión de lo que se venía a llamar la geografía radical. Esta nueva corriente estuvo marcada en su evolución por distintas líneas de trabajo que abarcaban el liberalismo, el movimiento libertario y el marxismo estructuralismo. A la radical le siguieron las dos últimas corrientes del pensamiento geográfico, la geografía realista inspirada en la teoría de la estructuración del sociólogo Giddens, que trata de integrar elementos de la hermenéutica con el marxismo estructural; y por último, la geografía posmoderna que ofrece un programa de deconstrucción y de crítica al modernismo, así como un acercamiento al humanismo geográfico.

\subsection{La geografía radical}

Surge como respuesta a la crisis del capitalismo, a la guerra de Vietnam, y al mayo del 68. Ofreció distintas líneas de actuación: la primera de ellas, fue la liberal o geografía del bienestar de D. Smith (1971), y a ella siguieron los planteamientos a favor y en contra sobre la idoneidad de la teoría marxista para comprender el espacio por parte de Quaini (1974), Lacoste (1976), Peet (1977) y Claval (1977). Desde un planteamiento libertario la revista francesa Hérodote recuperaba la influencia de los clásicos griegos (Heródoto y Estrabón) así como de Reclus para afirmar que la geografía sirve ante todo para hacer la guerra y para organizar los territorios con objeto de controlar mejor a los hombres sobre los que ejerce su autoridad el aparato estatal (Lacoste, 1976: 8-12). La línea que se consolidó como definitiva y mayoritaria, desde 1974, sería la que combinaría los métodos marxistas y estructuralistas.

El marxismo estructural de Althusser y las variantes del estructuralismo que ofrecían otros autores (Castells, Gurvitch, Lefebvre, Levi-Strauss y Piaget) venía a defender un 
método donde los fenómenos son considerados de forma integrada como elementos de una estructura. Aportación que posibilitó la aparición de un estructuralismo geográfico. A partir de los setenta, los geógrafos, en conexión con los sociólogos (Castells y Lefebvre) pusieron su mirada en las relaciones entre el espacio y el poder, o más concretamente en el espacio social.

Hasta ese momento la geografía había olvidado su análisis del espacio, se ha dicho que la geografía regional al buscar su acomodo en la síntesis cayó en la desocialización, en un espacio de apariencias, situación que no fue remediada con la geografía cuantitativa pues contribuyó poco a su conocimiento. Hasta la llegada de esta nueva corriente y su preocupación por el espacio, la geografía se había convertido en una ciencia sin objeto de estudio claramente definido. Se había renunciado a la esencia misma de la geografía en beneficio de los saberes instrumentales (Estébanez, 1996: 16-17).

Para comprender la aportación al estudio del espacio social nos centraremos en David Harvey y en Milton Santos. El primero de ellos, previamente había defendido los postulados del paradigma neopositivista, para posteriormente incorporar el espacio a la teoría estructuralista y marxista; el segundo, une su estructuralismo marxista al humanismo existencial de Sartre. A ellos se les debe un importante esfuerzo por consolidar a la geografía dentro de la teoría social, desde una epistemología materialista y dialéctica, no exclusivamente marxista.

Milton Santos en su obra Por una Geografía nueva (1978) traducida en nuestro país en 1990 no sólo hacía un análisis crítico de la evolución de la geografía, de su «discursión narcisista» por haberse preocupado más de su propia historia que de su objeto de estudio, lo que la convertía en «viuda del espacio», sino que además confirmaba que el espacio que le interesaba investigar, desde la periferia, era el espacio banal, el espacio verdaderamente humano, el espacio de toda la gente y no el espacio al servicio del capital y de unos pocos. En nuestra universidad inició un debate a comienzos del segundo quinquenio de los ochenta sobre la globalización, cuando aún no se hablaba de este tema. Afirmó que se estaba configurando un «sistema mundial» que iba a posibilitar cambios profundos, generalizados e inmediatos (Santos, 1988: 29), donde la tierra se convertía en solo y único mundo, asistiéndose de esta forma a la refundación de la tierra como totalidad, un espacio de la mundialización a diferentes niveles, intensidades y orientaciones (Santos, 1993:6970), sobre el que regirán una globalización «perversa» basada en el capitalismo mundial o neoliberalismo. El nuevo orden global o período técnico-científico-informacional que viene a sustituir a la revolución industrial, tratará de imponer a todos los lugares una única racionalidad, de forma que cada lugar será al mismo tiempo objeto de una razón global y de una razón local, conviviendo armónicamente (Santos, 1996: 272-273). Al final de su obra vuelve a insistir en el espacio de todos los individuos, en una geografía de la existencia y de la vida, en la necesidad de una teoría social crítica desde la cual se pueda recrear el mundo a partir del lugar (Santos, 1999: 38). En Por uma outra globalizaçao (2000) defiende un proyecto de sociedad utópica donde la centralidad de todas las acciones se localiza en el hombre y no en el dinero. Tras su fallecimiento, en el verano de 2001, nuevas aportaciones o estudios sobre su obra ayudarán a conocer su importante peso científico (Pillet, 1999; Panadero, 1999 y 2002; Zusman, 2002).

Harvey (1977) inició su teoría del espacio geográfico estableciendo la teoría de la utilización y de la renta del suelo (diferencial, monopolista y absoluta), y de su valor de uso y de cambio. En su análisis del espacio, del espacio como producto social, intentó comprender su significado simbólico y sus complejas influencias sobre el comportamiento. Desde su concepción de la geografía como ciencia, como ideología y como compromiso, llama la atención para interpretar que en el paso del capitalismo fordista al capitalismo 
global de acumulación flexible o posfordista es necesaria una nueva vuelta de la comprensión tiempo-espacio en la organización del capitalismo (Harvey, 1989). En su última obra Espacios de esperanza publicada en 2000 y traducida a nuestra lengua tres años después, en calidad de geógrafo marxista aborda dos temas, la globalización y las condiciones de producción del cuerpo proletario, insiste en la combinación conjunta del espacio y del tiempo para analizar la globalización económica y el «nexo global/local», desde su reciente fascinación por los conocimientos locales. Propone que a la producción social del espacio y del tiempo debe incorporarse el pensamiento utópico, un utopismo dialéctico espaciotemporal que «apunte hacia diferentes trayectorias para los desarrollos geográficos humanos desiguales». Todo ello requiere la perspectiva de una larga y permanente revolución histórica y geográfica, considerando útil las prácticas políticas transformadoras, con el fin de crear una totalidad evolutiva (Harvey, 2003: 106, 226 y 288). Su materialismo histórico-geográfico se basa en un proceso de producción desigual en el tiempo y en el espacio (Folch-Serra, 1997: 200). Se ha afirmado recientemente que establece una inteligente teoría de la crisis aportando un nuevo enfoque al análisis marxista, espacializando la dialéctica (Constenla, 2003: 33).

La actualidad de la obra de estos dos autores, su preocupación por el espacio social dentro de la conexión espacio-tiempo, como realidad unitaria, y sus propuestas utópicas, hacen de ambas aportaciones un análisis actualizado de la vieja geografía radical de los setenta. A estas coincidencias podemos unir, en ambos, su rechazo a los planteamientos posmodernos.

\subsection{La geografía realista}

Los fracasos de la originaria geografía radical se debieron a haber puesto mayor acento en la teoría que en la práctica, y también por haber pasado de la economía política al estructuralismo, sin tener en cuenta las acciones del ser humano. Esta ausencia justificó la aparición de una nueva corriente que combina el estructuralismo social y espacial con la perspectiva humanista. O más concretamente la teoría social de la estructuración del sociólogo A. Giddens (1979 y 1981) que integraba elementos de la hermenéutica y del estructuralismo, aspirando a comprender las interacciones de la acción humana, como base para una teoría social del espacio y del tiempo, este último basado en la geografía del tiempo o cronogeografía de Hägerstrand.

Según los geógrafos Peet y Thrift (1989), el realismo es una filosofía de la ciencia basada en el uso de la abstracción como medio de identificación de las estructuras sociales particulares, que admite la explicación estructural junto a una fuerte carga de escepticismo en la propia teoría (Mata, 1995: 101-103). Se ha afirmado que esta geografía venía a suponer una clara combinación de elementos marxistas y fenomenológicos donde destacan Massey, Thrift, Gregory y Sayer.

En línea con la revalorización del contexto espacial, Thrift (1983 y 1989) hizo hincapié en la necesidad de una geografía regional reconstruida donde la región se interpretaba como elemento imprescindible en la teorización social de la estructura espacial, y como proceso histórico de formación, reproducción y transformación de estructuras espaciales. Para Massey (1984 y 1989) la región se entiende como articulación de relaciones de producción en un espacio y en un lugar determinado y como organización espacial de los procesos sociales, teniendo en cuenta el modo de producción y la división social del espacio, a la vez que evidencia cómo los procesos de acumulación del capital o los procesos políticos actúan de manera diferente en cada lugar, según las características concretas. 
Mientras Gregory (1985) consideraba las regiones como espacios únicos e interdependientes, como estructuras homogéneas, distinguibles unas de otras (Albet, 1993: 15 y 18), Sayer (1984) las interpretaba en toda su heterogeneidad y complejidad combinando aspectos descriptivos y abstractos, idiográficos y nomotéticos, con una mayor carga de abstracción, como un sistema abierto que integra a la geografía física y a la humana (Barnes y Gregory, 1997: 112-113). Pero independientemente de estos esfuerzos, se ha criticado esta corriente geográfica por su proceso de desvalorización del territorio, por su preeminencia del tiempo (cronólogico) sobre el espacio (Santos y Silveira, 1996: 6).

\subsection{La geografía posmoderna}

Si la modernidad supone la concepción lineal del progreso, la sistematicidad, la objetividad, la racionalidad, la verdad de la ciencia; por el contrario, la posmodernidad se caracteriza por su incredulidad hacia cualquier teoría, por su rechazo a la filosofía, siendo sus principales defensores Foucault, Lyotard y Braudrillard (Norris, 1998: 218 y 243).

Desde planteamientos posfenomenológicos y postestructuralistas, el filósofo Derrida hablaba de la deconstrucción, de la destrucción de los códigos de la mente humana para reconstruirlos desde cero (Casariego, 1995: 878-880). El posmodernismo hace una defensa de la diferencia, de la flexibilidad, de la subjetividad, de la discontinuidad, de la indeterminación, y de la fragmentación. Surgió tras la crisis fordista y el hundimiento del comunismo, siendo expresión cultural del capitalismo avanzado o postindustrial.

La geografía posmoderna, nacida en la transición entre los ochenta y los noventa, se encuentra representada por Soja y Olsson. Este último relacionaba el poder con el conocimiento, interpreta la metáfora como instrumento de poder, y considera que la geografía es la interpretación de líneas; la cartografía del pensamiento, es decir, la cartografía como símbolo de lenguaje y de poder (Barnes y Gregory, 1997: 145-155). Una cartografía basada en «mapas invisibles»(Olsson, 1991: 85-92), unión de lenguaje y de representación, de relaciones entre el inconsciente colectivo y el inconsciente individual, penetrando en lo desconocido, a través de mapas invisibles. Se revelaba contra la propia disciplina al practicar un programa de deconstrucción donde la clave reside en la comprensión del lenguaje y de los signos. Afirmaba que el sentido de incertidumbre forma parte del presente mundo de la posmodernidad, un universo en el que la manipulación de los fenómenos invisibles se ha hecho mucho más provechosa que la manipulación de bienes materiales (Olsson, 1997: 47-48).

Soja, por su parte, mostraba su preocupación por construir una ontología del espacio basada en la teoría de la estructuración de Giddens. Reafirmaba la necesidad de «una reconceptualización radical de la epistemología, la elaboración de teorías y el análisis empírico» Señalaba que la organización del espacio social es un producto social que surge de la práctica social útil, y que las relaciones de poder y disciplina están registradas en la aparente espacialidad inocente de la vida social. Para añadir que, tanto en la vida económica como en la cultural, «la reestructuración espacial nos oculta consecuencias» en la actual sociedad (Soja, 1989: 6, 62, y 80). Posteriormente, Soja (1996) tomando de Lefebvre su lucha por el derecho a la diferencia defiende una política cultural de la diferencia y desarrolla desde una perspectiva marxista la concepción de una política cultural donde el espacio, el conocimiento y el poder se entrecruzan, para dar forma a los espacios de representación social, demostrando que «se puede ser posmoderno sin tener que renunciar a ser políticamente comprometido», es decir, que posmodernismo y marxismo no deben 
ser considerados como dos líneas antagónicas, abriendo nuevas líneas de investigación en la tensa relación que existe entre espacio y cultura o geografía cultural (Clua y Zusman, 2002: 113-115), aportando nuevas propuestas al llamado «giro cultural».

Las críticas a la geografía posmoderna proceden, entre otros, de Harvey y de Santos. El primero, repudiaba su anarquismo, su aceptación de lo efímero, de lo fragmentario, de lo discontinuo, y de lo caótico (Harvey, 1989). Santos junto a Silveira consideraban el posmodernismo como desterritorialización, como geografía metafórica, como propuesta deconstructiva hacia el vacío y la nada, como «nihilismo metodológico», y como glorificación de la fragmentación (Santos y Silveira, 1998: 107).

Por el contrario, existen otros autores que ven en este movimiento geográfico una clara conexión con la trama humanística, por las referencias al individuo, a las vivencias y emociones personales, a la particular interpretación del entorno, y especialmente por la preocupación por los espacios que nacen de la diferencia, de los espacios del feminismo, de la geografía de género. Se ha hablado de su preocupación por la dialéctica socioespacial y por la esfera local. Se le considera globalizador de diversos enfoques que van desde la geografía radical-marxista hasta la humanística (Coscuela, 1994; Albet, 1994). El posmodernismo y el postestructuralismo han instaurado una notable relajación teórica y epistemológica, promoviendo el eclécticismo y el relativismo en la teoría (Ortega, 2000: 495).

\section{El espacio local globalizado}

La rápida evolución de corrientes de pensamiento geográfico surgidas durante las últimas décadas ha originado un elevado nivel de escepticismo y eclecticismo conceptual que ha venido a unirse al pragmatismo defendido por el posmodernismo, lo que ha motivando el acercamiento de unas corrientes con otras sobre todo entre el humanismo fenomenológico y existencial, el estructuralismo radical, el realismo crítico y el posmodernismo, existiendo importantes puntos de diferencia y de unión en lo que se ha venido en llamar como pospositivismo o antipositivismo.

Eclecticismo o, también, como ocurre en nuestro país, persistencia de la geografía clásica regional a la que se le han ido incorporando los aspectos más destacados de las nuevas corrientes, los avances técnicos y una apuesta decidida por la aplicación (Olcina y Rico, 1995: 50), aunque esta última adolece en muchos casos de renovación conceptual y metodológica, a cambio de una clara actitud utilitarista por estar en los mercados, dependencia poco favorable para el desarrollo de una geografía social y crítica, como afirma Segrelles. La geografía aplicada no puede ni debe prescindir de un sólido basamento teórico (Segrelles, 2002: 21-29).

Analizar el espacio local globalizado o la conexión global-local, conectando el análisis del espacio subjetivo con el espacio social, despertando el interés y la crítica, obliga a mantener una dialéctica que capacite para desempeñar una tarea apasionante en una sociedad de la globalización que está originando, con su perversidad, desequilibrios cada vez más profundos, para lo que se hace imprescindible el asentamiento de valores humanos y científicos. Una dialéctica entre lo local y lo global que se convierte en el fundamento del espacio y del paisaje o territorio, como concepto teórico.

Milton Santos indicaba que paisaje y espacio no son sinónimos: El paisaje es el conjunto de formas que expresan las herencias que representan las sucesivas relaciones localizadas entre hombre y naturaleza, se utiliza frecuentemente en lugar de la expresión configuración territorial. El espacio, por el contrario, es la reunión de esas formas más la vida que las anima, resulta de la intrusión de la sociedad en esas formas-objetos, es por tanto, un conjunto de mercancías. Añade, también, que el espacio geográfico es un híbrido 
que participa igualmente de la condición de lo social y de lo físico (Santos, 1996: 86-87 y 74). De esta forma, como afirma el informe del Colegio de Geógrafos sobre El Desarrollo Local: ámbito de trabajo del geógrafo profesional «el espacio se articula y organiza en territorios, el geógrafo, analiza comprende y descifra el territorio, se convierte en un especialista del mismo. Constituye el profesional más capacitado sobre el territorio».

El análisis de la nueva realidad, de la dimensión territorial: Desarrollo Local-Desarrollo Rural (Rodríguez, 1999; Pillet y Plaza, 2001), como contrapunto y complemento del propio proceso de globalización, implica la renovación de nuestra disciplina, la redefinición de sus conceptos centrales y en particular del espacio, entendido como lugar, como elemento clave de las desigualdades (García Ballesteros, 1998); y sobre todo, necesita de la unidad de la geografía, de reconducir su actual proceso en una necesaria reconciliación y complementariedad entre las distintas ramas, tanto físicas como humanas (López Ontiveros, 1996: 124), acertando en la relación entre «generalismo y especializaciones» (Gómez Mendoza, 2001: 27). Colaboración que pasa por un criterio antropocéntrico que como han reconocido diversos autores, si la geografía no es humana no es geografía (Capel, 1998:5), o lo que es lo mismo, «la geografía es esencialmente geografía humana, es también sobre todo geografía regional» (García Fernández, 200: 34), lo que origina que la geografía física (Ortega, 2000: 544) no puede ser la geografía del medio físico o natural, ni subordinar lo social a lo físico. Esta necesaria unidad (Unwin, 1995: 289-291) entre Naturaleza y Sociedad podrá ser una realidad o un mito, pero no cabe duda que el estudio del espacio humanizado en la sociedad global, que hemos analizado en otra publicación reciente (Pillet, 2003), es el objetivo fundamental, a partir de una serie de temas clásicos y nuevos como la relación hombre-medio, la conexión espacial urbano-rural, las trasformaciones que se operan en dicha conexión a partir de los cambios que se están produciendo en una sociedad servoindustrial, y por último la referencia global-local.

Queremos concluir estas líneas llamando la atención de la responsabilidad que tenemos con los nuevos licenciados en Geografía, nunca como ahora había existido una preocupación social y política por lo territorial, por lo local. Desde otras profesiones y administraciones este tema y el uso de los SIG es tratado directa o tangencialmente, pero no cabe duda, que a la geografía, gracias a la labor de diversos geógrafos, se le reconoce la autoridad en esta temática. Debemos profundizar en el análisis integrado y no parcelado del territorio. El actual eclecticismo geográfico nos permite elaborar un corpus epistemológico con las principales aportaciones de los distintos paradigmas. El territorio puede ser interpretado como un sistema, cuyos subsistemas respondan a la interconexión de las distintas ramas de la geografía, fundamentales para el análisis y el diagnóstico. Nuestra respuesta debe ser inmediata, recordemos a Einstein cuando afirmaba que nunca pensaba en el futuro, llega enseguida.

\section{Bibliografía citada}

ALBET, A. (1993): «La nueva geografía regional o la construcción social de la región», en Anales de Geografía de la Universidad Complutense, $\mathrm{n}^{\mathrm{0}}$ 13, pp. 11-29.

ALBET, A. (1994): «Geografia, postmodernisme, geografia postmoderna: aportacions al debat», en Documents d'Anàlisi Geogràfica, no 24, pp. 7-11.

ARROYO, F. y PÉREZ, A. (1997): «Reflexiones sobre el espacio geográfico y su enseñanza», en Estudios Geográficos, no 229, pp. 513-543.

BARNES, T. y GREGORY, D. (Eds.) (1997): Reading Human Geography. The Poetics and Politics of Inquiry, London, Arnold.

BOIRA, J.V. (1992): «El estudio del espacio subjetivo (Geografía de la Percepción y del Comportamiento: una contribución al estado de la cuestión», en Estudios Geográficos, no 209, pp. 573-592. 
CAPEL, H. (1987): Geografía Humana y Ciencias Sociales, Barcelona, Montesinos.

CAPEL, H. (1998): «Una geografía para el siglo XXI», en Scripta Nova. Revista Electrónica de Geografía y Ciencias Sociales, no 19, pp. 1-11.

CASARIEGO RAMÍREZ, J. (1995): «Sobre el espacio y la post-modernidad. Una reflexión desde la experiencia norteamericana», en Ciudad y Territorio. Estudios Territoriales, nㅡㄹ 106, pp. 877 896.

CLUA, A. y ZUSMAN, P. (2002): «Más que palabras: otros mundos. Por una geografía cultural crítica», en Boletín de la Asociación de Geógrafos Españoles, nº 34, pp. 105-117.

CHORLEY, R. (1975): Nuevas tendencias en Geografía, Madrid, Instituto de Estudios de Administración Local.

CHORLEY, R. y HAGGETT, P. (1971): La geografía y los modelos socioeconómicos, Madrid. Instituto de Estudios de Administración Local.

COLEGIO DE GEÓGRAFOS (2003): El Desarrollo Local: ámbito de trabajo del geógrafo profesional. WWW.geografos.org

CONSTENLA VEGA, X. (2003). «La condición de la geografía: una introducción a la obra geográfica de David Harvey», en XVIII Congreso de la Asociación de Geógrafos Españoles, Barcelona, Universidad de Barcelona, pp. 26-36.

COSCUELA, A. (1994): «Darrera els postmodernistes, o les geografies culturals del capitalisme tardà», en Documents d'Analisi Geogràfica, no 24, pp. 13-58.

ESTÉBANEZ, J. (1990): «El carácter de la geografía», en PUYOL, R. Coord. Geografía humana, Madrid, Pirámide.

ESTÉBANEZ, J. (1996): «La geografía hoy, un reto educativo en el marco de la reforma educativa», en GRUPO DE DIDÁCTICA DE LA GEOGRAFÍA, AGE, III Jornadas de Didáctica de la Geografía, Madrid, Universidad Complutense de Madrid, pp. 15-29.

ESTÉBANEZ, J. y PÉREZ, C. (1990): «El espacio en los enfoques geográficos recientes», en ADÁNEZ ET ALT, Espacio y organización social, Madrid, Universidad Complutense, pp. 2134.

FOLCH-SERRA, M. (1997): «Estancia de David Harvey en Gerona», en Documents d'Anàlisi Geogràfica, no 30, pp. 197-201.

GARCÍA BALLESTEROS, A. (1998): «Métodos y técnicas cualitativas en geografía social», en GARCÍA BALLESTEROS, A. COORD. Métodos y técnicas cuatitativas en geografía social, Barcelona, Oikos-tau, pp. 13-26.

GARCÍA FERNÁNDEZ, J. (2001): «Geografía física o ciencias naturales», en Investigaciones Geográficas, 꿀 25, pp. 33-49.

GARCÍA RAMÓN, Mํㅡㄹ D. (1985): Teoría y método de la Geografía humana anglosajona, Barcelona, Ariel.

GÓMEZ MENDOZA, J. (1989): «Actualidad de la geografía regional», en Ería, Revista de Geografía, no 19-20, pp. 101-113.

GÓMEZ MENDOZA, J. (2001): «La Geografía española: final y principio de capítulo», en Actas del XVII Congreso de Geógrafos Españoles. Oviedo, pp. 19-27.

HABERMAS, J. (1982): Conocimiento e interés, Madrid, Taurus.

HABERMAS, J. (1988): Teoría de la acción comunicativa, Madrid, Taurus.

HARVEY, D. (1977): Urbanismo y desigualdad social, Madrid, Siglo XX.

HARVEY, D. (1989): The Condition of Postmodernity. An Enquiry into the Origins of Cultural Change, Oxford, Basil Blackwell.

HARVEY, D. (2003): Espacios de esperanza, Madrid, Akal.

KEMMIS, S. (1999): «La investigación-acción y la política de reflexión», en ANGULO, J.F. ET ALT. Desarrollo profesional docente: Política, investigación y práctica, Madrid, Akal, pp. 95118.

LACOSTE, Y. (1976): La géographie, ça sert, d'abord, à faire la guerre, Paris, Maspero.

LÓPEZ ONTIVEROS, A. (1996). «Evolución reciente de la investigación geográfica española», en Boletín de la Asociación de Geográfos Españoles, nº 21-22, pp. 119-132.

MATA, R. (1995): «Sobre la evolución reciente de la Geografía Regional: un estado de la cuestión», Breves Contribuciones del Instituto de Estudios Geográficos, no 9, pp. 67-130. 
MUÑOZ JIMÉNEZ, J. (1989): «Paisaje y Geografía», en Arbor, nº 518-519, pp. 219-233.

NOGUÉ, J. (1989): «Espacio, lugar, región: hacia una nueva perspectiva geográfica regional», en Boletín de la Asociación de Geógrafos Españoles, oㅜ 9, pp. 67-79.

NORRIS, CH. (1998): ¿Qué le ocurre a la postmodernidad? La teoría crítica y los límites de la filosofía, Madrid, Tecnos.

OLCINA, J. (1996): «La geografía hoy: reflexiones sobre el pensamiento geográfico, la región y la docencia de la geografía», en Investigaciones geográficas, nㅡㄴ 16, pp. 93-114.

OLCINA, J. y RICO, A.M. (1998): «La enseñanza de la geografía: realidades y propuestas», en Estudios de Ciencias Sociales1998, no 8, pp. 47-89.

OLSSON, G. (1991): «Invisible maps», en Geografiska Annaler, no 73, pp. 85-92.

OLSSON, G. (1997): «Misión imposible», en Anales de Geografía de la Universidad Complutense, $\mathrm{n}^{\mathrm{o}} 17$, pp. 40-51.

ORTEGA VALCÁRCEL, J. (2000): Los horizontes de la geografía. Teoría de la Geografía, Barcelona, Ariel.

PANADERO, M. (1999): «La dimensión temporal en la conformación del espacio geográfico (Leyendo a Milton Santos)», en Lecturas geográficas. Homenaje al profesor José Estébanez, Madrid, Editorial Complutense, pp. 567-579.

PANADERO, M. (2002): «Milton Santos (1926-2001). Su presencia en la geografía española», en Estudios Geográficos, no 245, pp. 745-755.

PÉREZ SIERRA, M. C. (1992): «La Geografía Humana ¿una ciencia sin núcleo?», en Anales de Geografía de la Universidad Complutense, ํㅡㄴ 12, pp. 79-92.

PILLET CAPDEPÓN, F. (1999): «El espacio y la influencia de Milton Santos», en PANADERO, M. y CEBRIÁN, F. (coords.): América Latina: Lógicas locales y lógicas globales, Cuenca, Universidad de Castilla-La Mancha, pp. 205-217.

PILLET CAPDEPÓN, F. (2001): «El espacio geográfico en el postpositivismo», en TONDA, E. y MULA, A. (coords.), Scripta in memoriam, Homenaje al profesor Jesús Rafael de Vera Ferre. Universidad de Alicante, pp. 319-328.

PILLET CAPDEPÓN, F. (2003): «El espacio geográfico y el estudio del espacio humanizado en la sociedad global», en Estudios Geográficos, nำ 250, pp. 47-62.

PILLET, F. y PLAZA, J. (Coords.) (2001): Lecciones de Desarrollo Rural. Ciudad Real. Universidad de Castilla-La Mancha y Asociación para el Desarrollo Rural de Castilla-La Mancha (CEDERCAM).

RODRÍGUEZ GUTIÉRREZ, F. (Ed.) (1999): Manual de Desarrollo Local. Gijón. Trea.

RODRÍGUEZ ROJO, M. (1997): Hacia una didáctica crítica, Madrid, La Muralla.

SALA, Ma y BATALLA, R. J. (1975): Teoría y métodos en Geografía física, Madrid, Síntesis.

SANTOS, M. (1988): «Nuevo orden internacional y reorganización espacial», en PANADERO, COLE y SANTOS: Urbanización, subdesarrollo y crisis en América Latina, Albacete, Seminario de Geografía.

SANTOS, M. (1990): Por una Geografía nueva. Madrid, Espasa Universidad.

SANTOS, M. (1993): «Los espacios de la globalización», Anales de Geografía de la Universidad Complutense, $\mathrm{n}^{\mathrm{O}}$ 13, pp. 69-77.

SANTOS, M. (1994): Técnica, espaço, tempo. São Paulo, Hucitec.

SANTOS, M. A. (1996): A natureza do espaço, São Paulo, Hucitec.

SANTOS, M. (1999): «El territorio: un agregado de espacios banales», en PANADERO, M.; CEBRIÁN, F. (coord.): América Latina: Lógicas locales, lógicas globales, Cuenca, Universidad de Castilla-La Mancha, pp. 31-39.

SANTOS, M. (2000): Por uma outra globalizaçâo. Rio de Janeiro, Efit. Record.

SANTOS, M.; SILVEIRA, M. L. (1998): «Más allá de las metáforas...Una geografía de la globalización», en Estudios Geográficos, no $230,99-112$.

SANTOS, M. y SILVEIRA, M. L. (1996): «Globalización y geografía: la compartimentación del espacio», en CEPEIGE, , no 33, pp. 5-12.

SEGRELLES, J. A. (Dir.) (2002): Geografía Humana. Fundamentos, métodos y conceptos. Alicante. ECU. Universidad de Alicante.

SCHAEFER, F. (1974): Excepcionalismo en Geografía, Barcelona, Ediciones de la Universidad de Barcelona. 
SOJA, E. W. (1989): Postmodern Geographies: the Reassertion of Space in Critical SocialTheory, London, Verso.

UNWIN, T. (1995): El lugar de la geografía, Madrid, Cátedra.

ZUSMAN, P. (2002): «Milton Santos, Su legado teórico y existencial (1926-2001)», en Documents d'Anàlisi Geogràfica, no 40, pp. 205-219. 